\title{
Hydrochloride pioglitazone protects diabetic rats against podocyte injury through preserving glomerular podocalyxin expression
}

\author{
O cloridrato de pioglitazona protege ratos diabéticos \\ contra a injúria aos podócitos por meio da preservação \\ da expressão de podocalixina glomerular
}

Yan Xing', Shandong Ye', Yumi Chen ${ }^{2}$, Wen $\mathrm{Hu}^{3}$, Yan Chen ${ }^{4}$

\footnotetext{
Department of Endocrinology, Anhui Provincial Hospital, Hefei, China

2 Department of Nephrology, Anhui Provincial Hospital, Hefei, China ${ }^{3}$ Department of Pathology, Anhui Provincial Hospital, Hefei, China ${ }^{4}$ Endocrinological Laboratory, Anhui Provincial Hospital, Hefei, China
}

Correspondence to: Shandong Ye ysd196406@163.com

\section{Received on Nov/26/2013} Accepted on Jun/4/2014

DOI: 10.1590/0004-2730000003141

\begin{abstract}
Objective: We sought to test the effect of different dosages of pioglitazone (PIO) on the glomerular expression of podocalyxin and urinary sediment podocalyxin excretion and to explore the potential renoprotective mechanism. Mlaterials and methods: Type 1 diabetes induced with streptozotocin $(65 \mathrm{mg} / \mathrm{kg})$ in 36 male Sprague-Dawley rats were randomly allocated to be treated with vehicle or 10, 20, $30 \mathrm{mg} / \mathrm{kg} / \mathrm{d}$ PIO respectively for 8 weeks. Eight rats were enrolled in the normal control group. Results: At $8^{\text {th }}$ week, rats were sacrificed for the observation of kidney injury through electron microscope. Glomerular podocalyxin production including mRNA and protein were determined by RT-PCR and immunohistochemistry respectively. Levels of urinary albumin excretion and urinary sediment podocalyxin, kidney injury index were all significantly increased, whereas expression of glomerular podocalyxin protein and mRNA were decreased significantly in diabetic rats compared to normal control. Dosages-dependent analysis revealed that protective effect of PIO ameliorated the physiopathological changes and reached a peak at dosage of $20 \mathrm{mg} / \mathrm{kg} / \mathrm{d}$. Conclusion: PIO could alleviate diabetic kidney injury in a dose-dependent pattern and the role may be associated with restraining urinary sediment podocalyxin excretion and preserving the glomerular podocalyxin expression. Arq Bras Endocrinol Metab. 2014;58(6):630-9
\end{abstract}

Keywords

Diabetic nephropathy; podocalyxin; pioglitazone; podocyte; proteinuria

\section{RESUMO}

Objetivo: Buscamos testar os efeitos de diferentes doses de pioglitazona (PIO) sobre a expressão glomerular de podocalixina e sobre a excreção de podocalixina em células do sedimento urinário, além de explorar o potencial mecanismo de proteção renal. Materiais e métodos: 0 diabetes tipo 1 foi induzido em 36 ratos Sprague-Dawley machos com estreptozotocina ( $65 \mathrm{mg} / \mathrm{kg}$ ). Os animais foram tratados apenas com o veículo, ou com 10, 20, $30 \mathrm{mg} / \mathrm{kg} / \mathrm{d}$ de PIO por 8 semanas. Oito ratos foram colocados no grupo controle. Resultados: Na oitava semana, os ratos foram sacrificados para se observar a lesão renal em microscopia eletrônica. A produção de podocalixina glomerular, incluindo mRNA e proteína, foi determinada por RT-PCR e imuno-histoquímica, respectivamente. Os níveis urinários de albumina e podocalixina nas células do sedimento urinário e o índice de lesão renal estavam todos significativamente aumentados, enquanto a expressão glomerular da proteína podocalixina e do mRNA estava significativamente diminuída em ratos diabéticos comparados com o controle normal. A análise dos efeitos dose-dependentes revelou que o efeito protetor da PIO melhorou as mudanças fisiopatológicas e atingiu um pico na dose de $20 \mathrm{mg} / \mathrm{kg} /$ dia. Conclusão: A PIO pode melhorar a injúria renal de forma dose-dependente e este papel pode estar associado com a prevenção da excreção de podocalixina nas células do sedimento urinário e com a preservação da expressão glomerular de podocalixina. Arq Bras Endocrinol Metab. 2014;58(6):630-9

Palavras-chave

Nefropatia diabética; podocalixina; pioglitazona; podócito; proteinúria 


\section{INTRODUCTION}

$\mathrm{D}$ iabetic chronic kidney disease (DCKD), a major cause of end-stage renal failure in many countries, is characterized by decreased glomerular filtration rate, proteinuria, mesangial proliferation, tubulointerstitial fibrosis and podocytopathies etc. $(1,2)$. Numerous studies have increasingly pointed to podocyte, terminally differentiated cell in the glomerular as a key target of diabetic kidney disease onset and progression $(1,3)$. As early as 1996, it was demonstrated that podocyte loss occurred owing to lack of proliferation, which leaded to denudation of the glomerular basement membrane $(\mathrm{GBM})$ and finally resulted in segmental glomerulosclerosis after adhesion with Bowman capsule (4). Alternatively, podocyte could be shed in the urine $(5,6)$. To detect earlier functional abnormalities in podocyte, several recent reports have focused on the expression of podocyte-associated proteins $(7,8)$.

Podocalyxin is a sialomucin most closely related to CD34 and endoglycan. It is expressed by kidney podocyte, hematopoietic progenitors, vascular endothelia, and a subset of neurons. Null mice for podocalyxin have immature glomeruli with their slit diaphragms replaced by tight and adherent junctions. They die soon after birth due to failure of podocyte to develop foot processes (9). Podocalyxin is indispensable for normal kidney development. Aberrant expression of podocalyxin participates in podocyte-related renal diseases, including DCKD (10).

It is necessary to evaluate oral glucose-lowering agents not only for their value in achieving glycemic control but also for their impact on long-term complication of diabetes. Thiazolidinediones (TZDs), such as pioglitazone (PIO), are ligand for the nuclear receptor peroxisome proliferator-activated receptor (PPAR- $\gamma$ ). They are widely used for diabetes therapy as insulinsensitizing agents. Recent studies have demonstrated that TZDs could reduce albuminuria in patients with type 2 diabetics and diabetic animals $(11,12)$. The protective effect may be partly related to its effect in alleviating podocyte injury. In the present study, we want to explore whether PIO could alleviate podocyte injury in diabetic rats by preserving glomerular podocalyxin expression beyond the glycemic control. So we decided to develop type 1 diabetes instead of type 2 diabetes animal model. Streptozotocin-induced TIDM models, which is hallmarked by destruction of pancreatic $\beta$ cells and irreversible insulin deficiency. Based on the changes, TZDs could not exert its hypoglycemic effect in the animal model.

Moreover, we aimed to investigate whether PIO could alleviate renal injury in diabetic rats by preventing the downregulation of podocyte-associated protein podocalyxin in a dose-dependent manner.

\section{MATERIALS AND METHODS}

\section{Animals and husbandry}

Crl: $\mathrm{CD}(\mathrm{SD})$ rats $(\mathrm{n}=50 ; 8$ weeks old with weight of $195 \pm 20 \mathrm{~g}$ ) were purchased from the Experimental Animal Center of Anhui Medical University (Hefei, China), which certified them to be free of mycoplasma, adventitious viruses, respiratory and enteric bacteria, and ecto- and endoparasites. This health status was monitored by use of a sentinel program and could be maintained throughout the experiments. The rats were kept in groups of five or six in clear polypropylene cages $(51 \times 41 \times 22 \mathrm{~cm})$ on hardwood bedding and acclimated for $7 \mathrm{~d}$ before initiation of the study. Rats received tap water and rodent chow (TROPHIC Animal Feed High-tech Co., Ltd, China) ad libitum. Throughout the experiment the animals were kept under artificial conditions of light $(14 \mathrm{~h} / 10 \mathrm{~h}$ light cycle, light on at $7 \mathrm{a} . \mathrm{m}$.$) , temperature \left(23 \pm 1^{\circ} \mathrm{C}\right)$ and humidity $(65 \pm 10 \%)$. Procedures involving animals and their care were performed in accordance with the Animal Care and Use Committee of Anhui Medical University. All efforts were made to minimize animal suffering. Streptozotocin-induced diabetes (Type 1) model is well established for investigating diabetes mellitus (13). After an overnight fasting, 8 rats were chose randomly to receive citrate buffer intraperitoneal injection as normal control group, and type 1 diabetic model was induced by a single intraperitoneal injection of streptozotocin (Sigma-Aldrich, St Louis, MO, USA, freshly dissolved in $0.1 \mathrm{M}$ citrate buffer, $\mathrm{pH} 4.3$ ) at a large dose of $65 \mathrm{mg} / \mathrm{kg}$ of body weight to the remaining 42 rats. Seventy-two hours later, peripheral blood was harvested from vena caudalis to evaluate the blood glucose level. Animals were considered to be type 1 diabetic rats if they had peripheral blood glucose concentrations of $16.7 \mathrm{mmol} / \mathrm{L}$ or greater in addition to polyuria and other diabetic features. Six rats died of diabetic ketoacidosis within the 48 hours. Four rats died of tail infection throughout the research. 


\section{Experiment grouping design}

After one week of diabetic model establishment, the living 32 diabetic rats were randomly divided into four subgroups as group DM, DR1, DR2 and DR3 ( $\mathrm{n}=8$ for each).

Grouping was exhibited as follows: (1) group NC: normal control rats gavaged with vehicle alone; (2) group DM: STZ-treated rats gavaged with vehicle alone; (3-5) three PIO-treatment groups (group DRl, DR2, DR3): STZ-induced diabetic rats gavaged with PIO at dose of $10 \mathrm{mg} / \mathrm{kg}$ (group DRl), $20 \mathrm{mg} / \mathrm{kg}$ (group DR2) and $30 \mathrm{mg} / \mathrm{kg}$ (group DR3) body weight once daily respectively.

\section{Parameters for further research}

Hydrochloride PIO (Jiangsu Hengrui Medicine Co., Ltd, Lianyungang, China) was crushed into powder and dissolved in $0.9 \%$ physiological saline before intragastric administration. The day the drug administration started was defined as week $0.10 \mathrm{ml}$ of urine samples were collected at the $8^{\text {th }}$ week with metabolic cages and preserved at $-70^{\circ} \mathrm{C}$ to test urinary albumin (UALB), urinary creatinine and urinary sediment podocalyxin. Peripheral blood glucose was tested 2-3 times per week. To prevent death induced by emergency such as diabetic ketoacidosis, all the rats with peripheral blood glucose more than $33.3 \mathrm{mmol} / \mathrm{L}$ were injected sc with 0.5 unit insulin glargine 2-3 times per week according the blood sugar level to keep the blood sugar levels range between 20 to $30 \mathrm{mmol} / \mathrm{L}$. Following 8 weeks observation, all animals were anaesthetized (after $14 \mathrm{~h}$ of starvation) by intraperitoneal injection of chloral hydrate (300 $\mathrm{mg} / \mathrm{kg}$ body weight), then blood sample was collected for measuring hemoglobin Alc (HbAlc), lipid profile, BUN, serum creatinine. The kidneys were immediately enucleated and weighed separately, then divided into two parts for pathological and immunohistochemical analysis and mRNA extraction.

We have used chloral hydrate to anesthetize rat for a few years. If chloral hydrate caused significant respiratory depression in rat we would expect to have a high rate of overdose. But according to our experience, we found the opposite to be true. We have not observed pain behavior during the process of anesthesia, such as vocalization or movement in response to incision. Although chloral hydrate has been implicated in causing peritonitis and/or adynamic ileus in rodents, lesser concentrations ( $5 \%$ in our experiment) could minimize or eliminate this adverse effect. Finally, some reports demonstrated that there is uncompensated metabolic acidosis, hypotension, bradycardia and hypothermia during the process of anesthesia. In our experiment, physiologic measurements during operation: Heart rate (HR, beats/min), respiratory rate (RR, breaths/min) and rectal temperature $\left(\mathrm{T},{ }^{\circ} \mathrm{C}\right)$ were monitored in each mouse per group. We have not found any abnormality in the research.

\section{Statement of ethics}

The study protocol was approved by the Ethics Committee of Anhui Medical University, Medical Institution Animal Care and Research Advisory Committee (Hefei, China). These animals were maintained according to the guidelines established in "Guide for the care and use of laboratory animals" prepared by the Committee on Care and Use of Laboratory Animals of the Institute of Laboratory Animal Resources Commission on Life Sciences, National Research Council, USA (1985).

\section{Laboratory assay}

Peripheral blood glucose was tested by Accu-Chek Active System (Roche Diagnostics GmbH, Germany). UALB was measured by radioimmunoassay using a commercially available RIA kit (Northern Biotechnology Research Institute, Beijing, China). The intra- and inter-assay coefficients of variability were $<7 \%$ and $8 \%$, respectively, and the sensitivity is $0.5 \mu \mathrm{g} / \mathrm{mL}$. Creatine both in urine and serum were detected by picric kinetic analysis (Rongsheng, Shanghai, China). Urinary albumin level was expressed as UALB to urinary creatinine ratio $(\mathrm{mg} / \mathrm{g}, \mathrm{UACR})$. BUN was analyzed by urease method (Rongsheng, Shanghai, China). Creatinine clearance rate was calculated and normalized for body weight. Affinity chromatography was used to measure HbAlc (Primus, USA). Levels of lipid profile were analyzed with an automatic biochemistry analyzer (HITACHI 7600-020, HITACHI Ltd. Tokyo, Japan), including total cholesterol (TC), high-density lipoprotein cholesterol (HDL-c), low-density lipoprotein cholesterol (LDL-c), and triglyceride (TG). All the parameters mentioned above were completed in Endocrinological Laboratory of Anhui Provincial Hospital.

\section{ELISA to serially measure urinary sediment podocalyxin}

The quantification of urinary sediment podocalyxin was performed as reported previously by Kanno and 
cols. (14). Podocalyxin ELISA system (Quantikine kit for Rat, podocalyxin Immunoassay, R\&D Systems, and Minneapolis, MN, USA) was utilized according to the manufacturer's instructions. The intra- and inter-assay coefficient of variability was $<9 \%$ and $11 \%$, respectively. Each sample was measured in duplicate. Urinary sediment podocalyxin level was expressed as the ratio of urinary sediment podocalyxin concentration to urinary creatinine concentration $(\mu \mathrm{g} / \mathrm{g}$, UPCR).

\section{Histopathological changes in experimental animals}

Part of renal cortex was fixed in $2.5 \%$ glutaraldehyde, and then $1 \%$ osmic acid, dehydrated, and embedded in Epoxy resin. Ultrathin sections were prepared and stained with lead citrate for transmission electron microscopy (JEM 1200EX, Jeol, Tokyo, Japan). Five micrographs at a magnification of 20,000 were randomly selected from each specimen at different views. The total length of glomerular basement membrane (GBM) and the fused foot processes (FP) were measured as $\mathrm{X}$ and $\mathrm{Y}$. Foot process fusion ratio (FPFR) was expressed as $\mathrm{Y} / \mathrm{X}$. GBM was divided into several parts with $\mathrm{l} \mathrm{cm}$ as minimum unit and the thickness of each part was measured under the electron microscope. A sum of GBM thickness was calculated as A and the quantity of all parts was calculated as $\mathrm{B}$. The average width of GBM (GBMW) was expressed as A/B. All the parameters were measured by the Image Pro Plus image analysis system (version 6.0, Media Cybernetics, Silver Spring, MD). Each slide was assessed by a pathologist blinded to the experimental conditions.

\section{Immunohistochemistry for quantification of podocalyxin per glomerulus cross-section}

Paraffin-embedded tissues were cut into $4 \mu \mathrm{m}$ sections. After deparaffinization and dehydration in an ethanol series, antigen retrieval was performed by heating in a microwave oven $(750 \mathrm{~W}$ for $5 \mathrm{~min} \times 5$ times in citrate buffer). After cooling, endogenous peroxidase activity was inhibited by incubation in 3\% hydrogen peroxide $\left(\mathrm{H}_{2} \mathrm{O}_{2}\right)$ in methanol for $10 \mathrm{~min}$, followed by three washings in PBS ( $\mathrm{pH} 7.2$ ) for $15 \mathrm{~min}$. Nonspecific protein binding was blocked with $20 \%$ normal goat serum in TBS ( 50 mM Tris- $\mathrm{HCl} / 150 \mathrm{~mL} \mathrm{NaCl}$, pH 7.6, Beijing ZhongShan Biotechological Ltd., P.R. China) at room temperature for $10 \mathrm{~min}$. After blotting up the serum with filter paper, the sections were then incubated overnight with a polyclonal rabbit antibody directed against
Podocalyxin (Beijing Biosynthesis Biotechnology Co., LTD) dissolved in PBS in a 1:200 dilution at $4^{\circ} \mathrm{C}$ in a refrigerator followed next day by three rinses in PBS ( $\mathrm{pH}$ 7.2) for a total of $9 \mathrm{~min}$. Then staining was executed by Elivision ${ }^{\mathrm{TM}}$ plus two-step system, then rinsed 3 times in PBS and stained twice, first in a fresh mixture of diaminobenzidine (DAB) for $10 \mathrm{~min}(25 \mathrm{mg} \mathrm{DAB}$ $+50 \mathrm{ml}$ TBS and $0.15 \mathrm{ml} 30 \% \mathrm{H}_{2} \mathrm{O}_{2}$ ), and then in hematoxylin for 2-3 min. After that, they were washed in distilled water for $10 \mathrm{~min}$, dehydrated in ethanol, and coverslips were applied. Slides lacking primary antibody were used as controls. Image Pro Plus (IPP) is one of the digital image analysis systems engineered to quantify immunohistochemistry staining levels, which has been used in several studies to assess the immunohistochemistry expression. Briefly, 10 digital images at 1360 $\times 1024$ pixel resolution at $400 \times$ magnification were captured by the Micropublisher 5.0 (Qimaging, Canada) coupled to an Olympus BX-41 microscope (Olympus). The podocalyxin-positive cell would be expected to show yellowish brown staining of the cytoplasm (podocalyxin positive) under the microscope, whereas the negative cells should not be stained (podocalyxin negative). The optical density was calibrated and the area of interest was set through: hue, 0B30; saturation, 0B255; intensity, $0 \mathrm{~B} 255$. And then the images were converted to gray scale images, and the values were counted. A series of 10 random images on several sections was taken for each immunostained parameter to obtain a mean value for statistical comparison. Immunohistochemical parameters assessed in that area detected include mean stained area, mean intensity of stain, and mean integrated optical density (mean IOD). Mean integral calculus of the mean stained area times the intensity of stain in each pixel in the glomerular indicates the total amount of staining material in that glomerular (mean IOD).

\section{Semiquantitative analysis of the glomerular podocalyxin mRNA expression}

Outer cortex was minced in 3 to $4 \mathrm{~mm}$ fragments, and then was homogenized in $1 \mathrm{~mL}$ of Trizol reagent (Invitrogen, Carlsbad, CA, USA) per $50 \mathrm{mg}$ of tissue using power homogenizer. RNA extraction was performed according to the protocol recommended by the manufacturer. The amount of RNA was estimated by spectrophotometry at $260 \mathrm{~nm}$, and then $0.3 \mu \mathrm{g}$ of the total RNA was used to make the first-strand cDNA with a kit (PrimeScript RT master mix, Takara biotechnology (Dalian) Co., Ltd.). $5 \mu \mathrm{L}$ of cDNA were 
used as templates for amplification of podocalyxin and GAPDH. The primers were 5'-GCA GGG CTT TGA ACC TCT TG-3' (forward primer) and 5'-GCT CTG TGA CAC TCG GAT TT-3' (reverse primer) for podocalyxin, generating a 343 bp fragment; 5'-AGA TCC ACA ACG GAT ACA TT-3' (forward primer) and 5'TCC CTC AAG ATT GTC AGC AA-3' (reverse primer) for housekeeping gene glyceraldehyde-3-phosphate dehydrogenase(GAPDH). The PCR conditions included predenaturation at $94^{\circ} \mathrm{C}$ for 5 minute and 38 cycles of denaturation at $95^{\circ} \mathrm{C}$ for $45 \mathrm{~s}$, annealing at $60.9^{\circ} \mathrm{C}$ (podocalyxin) or $59^{\circ} \mathrm{C}(\mathrm{GAPDH})$ for $30 \mathrm{~s}$ and extension at $72^{\circ} \mathrm{C}$ for $1 \mathrm{~min}$, and a final extension at $72^{\circ} \mathrm{C}$ for 7 minute. The amplified products were subjected to $1.5 \%$ agarose gel electrophoresis and the bands were captured followed by analysis of the optical density (Biosens 805, Shanghai Bio-Tech Co., Ltd). The expression of podocalyxin mRNA was normalized by that of GAPDH.

\section{Statistical analysis}

Data were expressed as the means \pm SD and were analyzed by Statistical Package for the Social Sciences 13.0 (SPSS 13.0 for Windows, SPSS 13 Inc, Chicago, Illinois, USA). Some non-normally distributed variables including urinary albumin, urinary sediment podocalyxin have to be compared with parametric tests after $\log$-transformation. The measurement data of multiple groups were compared with one-way ANOVA, the comparison between two groups was performed with
(LSD) T-Test, and a value of $P<0.05$ was considered significant. Correlations analysis was assessed by linear dependence relation. Differences were considered significant at $P$ values $<0.05$.

\section{RESULTS}

\section{Blood glucose, HbA1c, SCr, BUN, Ccr in experimental animals}

The various biochemical results for each group were presented in table 1. Compared with group NC, blood glucose, $\mathrm{HbAlc}, \mathrm{BUN}, \mathrm{SCr}$ and creatinine clearance rate $(\mathrm{Ccr})$ at the $8^{\text {th }}$ week were elevated significantly in diabetic rats (including group DM, DR1, DR2 and DR3). PIO treatment significantly reduced BUN in comparison with that in group DM, whereas there was no apparent difference in BUN among group DRl, DR2 and DR3.

\section{Effect of PIO on plasma lipids}

As shown in table 1 , reduced HDL-c, raised TG and LDL-c were exhibited in four diabetic groups as compared with group $\mathrm{NC}$ at the $8^{\text {th }}$ week. Following 8 weeks therapy, PIO treatment groups showed no dramatic changes in LDL-c levels, whereas HDL-c levels were significantly increased compared with group DM. Moreover, HDL-c level was higher in group DR2 and DR3 than that of group DRl. Significant reduction $(P$ $<0.05)$ in TG was found in PIO groups when com-

Table 1. Comparison of the levels of BG, HbA1C, SCr, BUN, TG, TC, HDL-C and LDL-C among five groups at the $8^{\text {th }}$ week

\begin{tabular}{|c|c|c|c|c|c|}
\hline \multirow{2}{*}{ Parameters } & \multicolumn{5}{|c|}{ Group } \\
\hline & NC $(n=8)$ & DM $(n=8)$ & DR1 $(n=8)$ & $\mathrm{DR} 2(\mathrm{n}=8)$ & DR3 $(n=8)$ \\
\hline $\mathrm{BG}(\mathrm{mmol} / \mathrm{L})$ & $4.00 \pm 0.77$ & $21.76 \pm 1.57^{\Delta}$ & $22.26 \pm 2.02^{\Delta}$ & $21.96 \pm 2.10^{\Delta}$ & $21.83 \pm 1.89^{\Delta}$ \\
\hline $\mathrm{HbA1c}(\%)$ & $3.80 \pm 0.57$ & $11.07 \pm 1.55^{\Delta}$ & $10.55 \pm 1.24^{\Delta}$ & $10.54 \pm 1.43^{\Delta}$ & $10.49 \pm 1.10^{\Delta}$ \\
\hline $\mathrm{SCr}(\mu \mathrm{mol} / \mathrm{L})$ & $55.10 \pm 8.04$ & $106.50 \pm 16.20^{\Delta}$ & $93.18 \pm 13.06^{\Delta}$ & $93.67 \pm 17.28^{\Delta}$ & $98.30 \pm 13.64^{\Delta}$ \\
\hline BUN (mmol/L) & $2.96 \pm 0.49$ & $10.01 \pm 1.52^{\Delta}$ & $8.12 \pm 1.02^{\Delta \star}$ & $7.80 \pm 1.28^{\Delta \star}$ & $7.16 \pm 0.88^{\Delta \star}$ \\
\hline $\operatorname{Ccr}(\mathrm{ml} / \mathrm{min} / 100 \mathrm{~g})$ & $0.42 \pm 0.16$ & $0.68 \pm 0.21^{\Delta}$ & $0.64 \pm 0.27^{\Delta}$ & $0.61 \pm 0.24^{\Delta}$ & $0.63 \pm 0.17^{\Delta}$ \\
\hline $\mathrm{TG}(\mathrm{mmol} / \mathrm{L})$ & $1.11 \pm 0.21$ & $1.74 \pm 0.24^{\Delta}$ & $1.43 \pm 0.35^{\Delta \Delta \star \star}$ & $1.43 \pm 0.10^{\Delta \Delta \star \star}$ & $1.41 \pm 0.39^{\Delta \Delta \star \star}$ \\
\hline $\mathrm{TC}$ (mmol/L) & $1.25 \pm 0.27$ & $1.57 \pm 0.35$ & $1.55 \pm 0.29$ & $1.53 \pm 0.39$ & $1.48 \pm 0.35$ \\
\hline $\mathrm{HDL}-\mathrm{C}(\mathrm{mmol} / \mathrm{L})$ & $1.24 \pm 0.22$ & $0.71 \pm 0.11^{\Delta}$ & $0.85 \pm 0.14^{\Delta}$ & $0.93 \pm 0.23^{\Delta \star \star}$ & $0.93 \pm 0.27^{\Delta \star \star}$ \\
\hline LDL-c (mmol/L) & $0.73 \pm 0.12$ & $1.28 \pm 0.23^{\Delta}$ & $1.12 \pm 0.25^{\Delta}$ & $1.16 \pm 0.17^{\Delta}$ & $1.09 \pm 0.18^{\Delta}$ \\
\hline
\end{tabular}

a Data were shown as mean \pm standard deviation.

Abbreviations: group NC: normal rats gavaged with vehicle alone; group DM: STZ-treated rats gavaged with vehicle alone; Group DR1: diabetic rats gavaged with PI0 at dose of 10 mg/kg; Group DR2: diabetic rats gavaged with PIO at dose of $20 \mathrm{mg} / \mathrm{kg}$; Group DR3: diabetic rats gavaged with PIO at dose of $30 \mathrm{mg} / \mathrm{kg}$.

${ }^{\Delta} \mathrm{P}<0.01,{ }^{\Delta \Delta} \mathrm{P}<0.05$ vs. group NC.

${ }^{\star} \mathrm{P}<0.01,{ }^{\star \star} \mathrm{P}<0.05$ vs. group DM. 
paring with group DM, but no significant difference in TG was found among three PIO treatment groups.

\section{Comparison of UPCR and UACR levels before and after treatment}

The changes of UPCR and UACR levels were presented in figure 1. At the baseline, UPCR and UACR in three PIO groups and group DM were similar to those in group NC. As shown in table 2, UACR showed an approximately 3.9 -fold increment and UPCR exhibited 5.6-fold increment in group DM at 8 weeks, as compared with those of the baseline level.

At the $8^{\text {th }}$ week, UACR in three PIO groups and UPCR in group DR2 and DR3 were decreased when compared with group DM $(P<0.05)$, whereas UPCR in group DRl was slightly lower than that of group $\mathrm{DM}(P>0.05)$. Moreover, UACR and UPCR in group DR2 and DR3 were lower than those in group DRl $(P<0.05)$. In addition, no dramatic changes of UPCR and UACR levels in group NC were observed throughout the study.

\section{Histopathologic changes in experimental animals}

As shown in table 2, the kidney weight/body weight ratios $(\mathrm{KI})$, a marker for the development of diabetic nephropathy, were almost doubled in group DM compared to group $\mathrm{NC}$ at the $8^{\text {th }}$ week, while restored by PIO administration. More importantly, the decrement of KI was significantly greater in group DR2 and DR3 than that in group DRI.

As shown in table 2 and figure 2, the width of glomerular basement membrane (GBMW) and ultrastructure of the podocyte as well as mesangial region in group $\mathrm{NC}$ were normal and foot process fusion rate (FPFR) was nearly $0.03 \%$. However, the FPFR reached approximately $87 \%$ in group DM. Figure 1 shows that both the foot process effacement and thickening of GBM were also observed in group DM. Meanwhile, some foot processes were completely ruined, even vanished and the architecture of GBM became ambiguous. However, through PIO treatment, both FPFR and glomerular GBMW in three dose groups were reduced. More importantly, the declining amplitudes
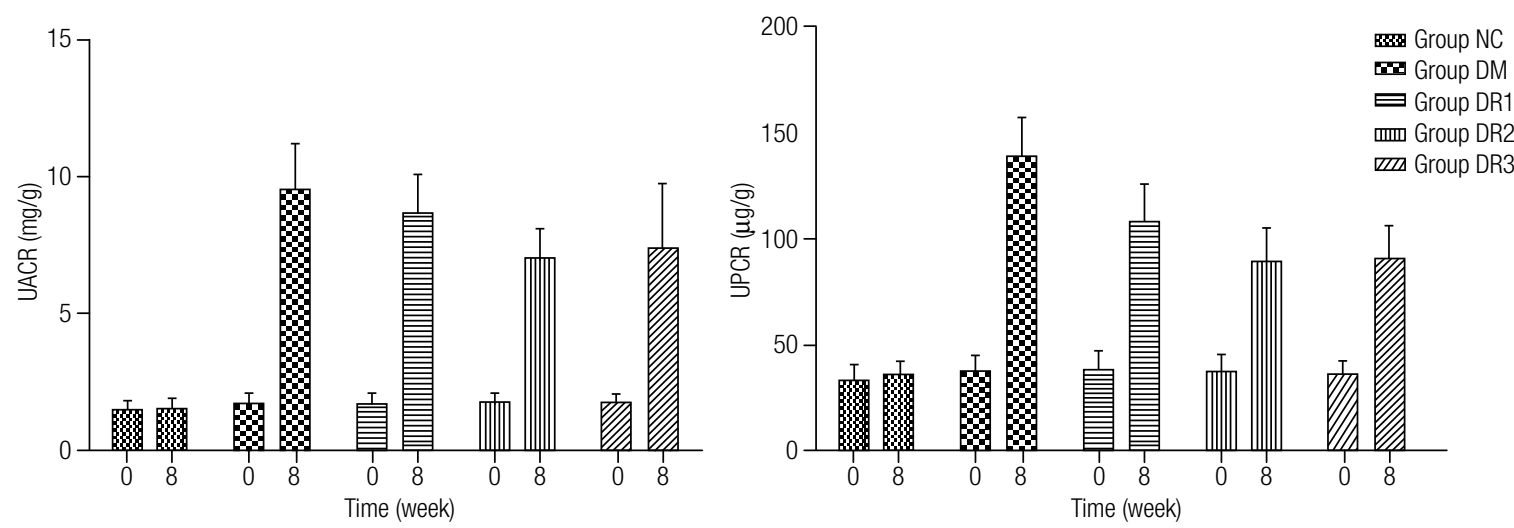

Figure 1. The changes of UPCR and UACR levels before and after 8 weeks of treatment. Kl: kidney weight/body weight ratio; for definitions of DM, DR1, DR2 and DR3, see table 1.

Table 2. Comparison of the levels of UPCR, UACR, KI, GBMW and FDFR among five groups at the $8^{\text {th }}$ week $^{\text {a }}$

\begin{tabular}{|c|c|c|c|c|c|}
\hline \multirow{2}{*}{ Parameters } & \multicolumn{5}{|c|}{ Group } \\
\hline & NC $(n=8)$ & $\mathrm{DM}(\mathrm{n}=8)$ & DR1 $(n=8)$ & DR2 $(n=8)$ & DR3 $(n=8)$ \\
\hline UACR $(\mathrm{mg} / \mathrm{g})$ & $35.05 \pm 6.75$ & $138.51 \pm 18.87^{\Delta}$ & $107.53 \pm 18.36^{\Delta \star}$ & $89.04 \pm 16.12^{\Delta \star}$ & $89.93 \pm 16.46^{\Delta \star \bullet}$ \\
\hline UPCR $(\mu \mathrm{g} / \mathrm{g})$ & $1.46 \pm 0.39$ & $9.50 \pm 1.67^{\Delta}$ & $8.62 \pm 1.46^{\Delta}$ & $7.01 \pm 1.07^{\Delta \star \varpi}$ & $7.33 \pm 2.40^{\Delta \star}$ \\
\hline $\mathrm{KI}(\times 10-3)$ & $3.07 \pm 0.43$ & $6.11 \pm 0.62^{\Delta}$ & $5.29 \pm 0.73^{\Delta \star}$ & $4.74 \pm 0.36^{\Delta \star \varpi}$ & $4.72 \pm 0.36^{\Delta \star \bullet}$ \\
\hline GBMW (nm) & $101.79 \pm 15.70$ & $294.07 \pm 29.31^{\Delta}$ & $210.43 \pm 16.83^{\Delta \star}$ & $132.03 \pm 17.98^{\Delta \Delta \star \varpi}$ & $129.66 \pm 18.3^{\Delta \Delta \star \varpi}$ \\
\hline FPFR (\%) & $0.03 \pm 0.02$ & $0.87 \pm 0.04^{\Delta}$ & $0.73 \pm 0.04^{\Delta \star}$ & $0.51 \pm 0.05^{\Delta \star \varpi}$ & $0.47 \pm 0.04^{\Delta \star \bullet}$ \\
\hline
\end{tabular}

a Data were shown as mean \pm standard deviation.

For definitions of DM, DR1, DR2 and DR3, see table 1.

${ }^{\Delta} \mathrm{P}<0.01 .{ }^{\Delta \Delta} \mathrm{P}<0.05$ vs. group NC. ${ }^{\star} \mathrm{P}<0.01$ vs. group DM. ${ }^{\bullet} \mathrm{P}<0.05$ vs. group DR1. 
of the parameters mentioned above were significantly greater in group DR2 and DR3 compared with group DRl (Figure 2).

\section{Immunohistochemical detection of podocalyxin in the glomeruli}

As illustrated in figure 2, podocalyxin protein was detected within the visceral surface of the Bowman's capsule, in the podocyte, with a membranous pattern of staining in normal control samples, which was decreased significantly in streptozotocin-induced diabetic rats, especially in group DM. The comparisons of glomerular podocalyxin protein expression representative by integral optical density (IOD) among the five groups at $8^{\text {th }}$ week were presented. As seen here, glomerular podocalyxin expressions in all treatment groups were dramatically increased after 8-week PIO administration, and this was more prominent in group DR2 and DR3 in comparison with group DRl (Figure 3).

\section{Expression of glomerular podocalyxin mRNA determined by RT-PCR}

Figure 3 shows that level of glomerular podocalyxin mRNA expression in group NC was significantly higher than that in group DM. PIO administration for 8 weeks significantly up-regulated the glomerular podocalyxin mRNA, whereas there was no dramatic difference among group DR1, DR2 and DR3 (Figure 4).

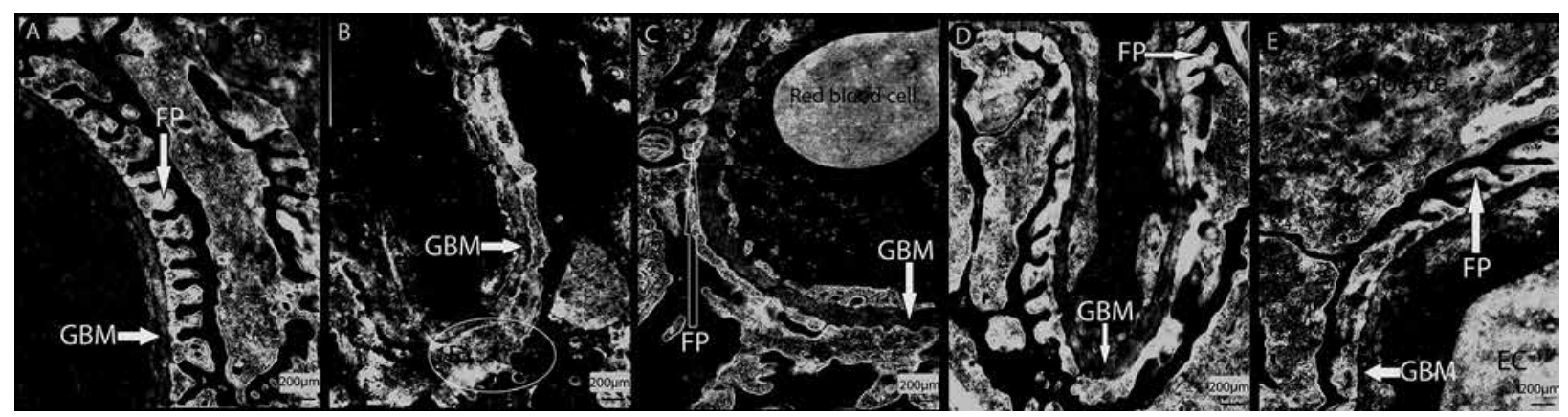

Figure 2. The representative renal tissues pathology in the experimental groups observed by electron microscope (uranium staining, $\times 20000$ ).

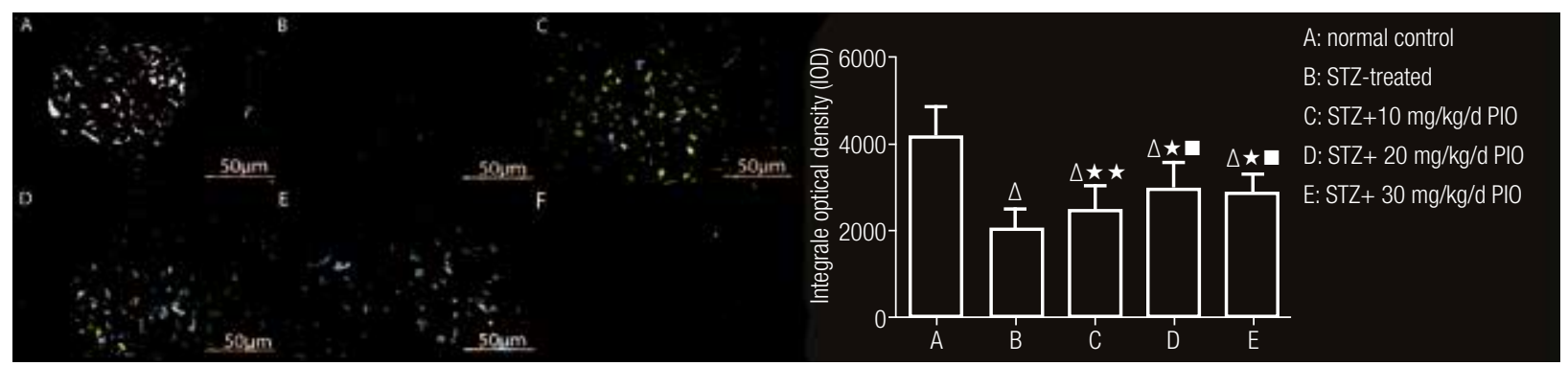

Figure 3. The podocalyxin-positive cell would be expected to show yellowish brown staining of the cytoplasm (podocalyxin positive) under the microscope, whereas the negative cells should not be stained (podocalyxin negative).

${ }^{*} \mathrm{P}<0.01$ vs. group NC. ${ }^{\Delta} \mathrm{P}<0.01 . \wedge \mathrm{P}<0.05$ vs. group DM. $\cdot \mathrm{P}<0.05$ vs. group DR1.

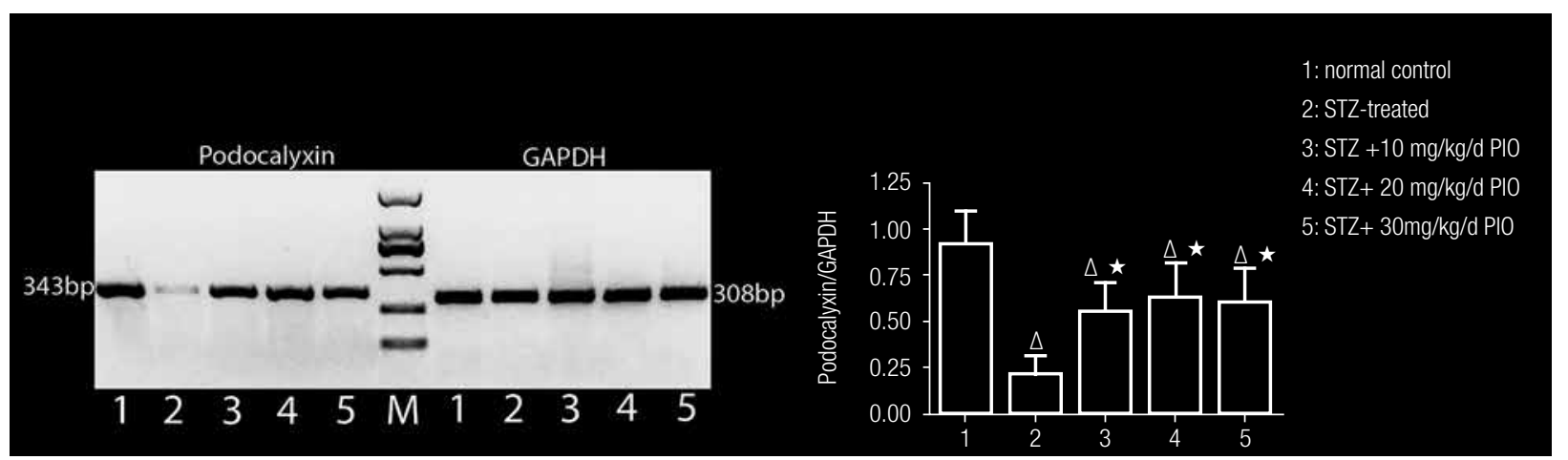

Figure 4. Comparison of glomerular mRNA expression. The expected lengths of PCR products are 343 base pairs (bp) for Podocalyxin and 308 bp for glyceraldehyde-3-phosphate dehydrogenase (GAPDH). The values were expressed as mean \pm standard deviation. 


\section{Related analysis}

As shown in figure 4, significant positive correlation between UPCR and UACR $(r=0.86, P<0.01)$ was detected.

\section{DISCUSSION}

Destruction of the podocyte included foot process effacement, apoptosis and detachment from the glomerular basement membrane. Podocalyxin is initially identified in glomeruli and known as podocalyxin-like protein 1 (PODXL or PCLPl). It is the most abundant heavily charged sialomucin expressed by podocyte, whose expression and distribution has been correlated with podocyte development $(15,16)$.

Through interactions with several intracellular proteins and at least one extracellular ligand, podocalyxin regulates both adhesion and cell morphology (17). Hara and cols. (18), reported that the amount of urinary sediment podocalyxin excretion apparently indicated the degree of the podocyte injury in glomerular diseases. The present study showed that UPCR was much more prominent and related positively to the UACR (which is one of the earliest clinical manifestation of diabetic nephropathy) after 9 weeks of streptozotocin administration, which provides a basis for an involvement of podocalyxin in the occurrence and development of proteinuria, consistent with previous reports (14). UACR, UPCR, FPFR, glomerular basement membrane width (GBMT) and KI were all elevated in diabetic rats compared with group $\mathrm{NC}$, whereas the expressions of glomerular podocalyxin protein and mRNA were significantly decreased. Reduced glomerular podocalyxin expression might contribute to expansion of effacement of foot process, considering the normal function of podocalyxin as an anti-adhesion molecule. Thus, we speculate that downregulation of glomerular podocalyxin expression leads to an increase in podocyte' adhesion between them and to the GBM as well, thus aggravating proteinuria and then resulting in diabetic glomerular sclerosis.

A single large dose of streptozotocin-induced rat model of type-1 diabetes mellitus was used in the present study $(19,20)$. By virtue of direct toxic effects of streptozotocin, as in human type 1 diabetes, immune destruction plays a role in inducing insulinopenic diabetes. As a result of immune-mediating insulitis and $\beta$ cell death, hence PIO was unable to enhance insulin sensitivity in type 1 diabetic rodent model. Our find- ings showed that no difference in blood glucose and HbAlc were observed between PIO treated groups and group DM, which provided further support for the view that TZDs have definite reno-protection beyond its hypoglycemic effect, consistent with previous reports $(21,22)$. Yoshioka and cols., reported firstly a possible renoprotective action of TZDs by an animal experiment with troglitazone more than 10 years ago (23), in which the compound remarkably reduced the urinary protein excretion in obese Zucker rats. In the present study, we showed that 8-week PIO treatment resulted in a significant reduction in UACR, UPCR, $\mathrm{KI}$ and pathological injury indices (representative by GBMW and FPFR). In addition, the parameters mentioned above in group DR2 and DR3 were lower than those in group DRl, whereas no significant differences were found between DR2 and DR3 group. Furthermore, downregulation in expression of glomerular podocalyxin protein and mRNA in group DM have been reversed in all the PIO-treated groups. It was notable that effect of $20 \mathrm{mg} / \mathrm{kg} / \mathrm{d}$ and $30 \mathrm{mg} / \mathrm{kg} / \mathrm{d}$ PIO was superior to that of $10 \mathrm{mg} / \mathrm{kg} / \mathrm{d}$ PIO in preserving the expression of glomerular podocalyxin protein. No significant difference was observed between DR2 and DR3, which suggested that the effect of PIO in preserving glomerular podocalyxin protein expression was dependent on difference on its dosages. Functional PPAR- $\gamma$ receptors have been identified in tubular segments and podocyte (24), which suggested that TZDs could alleviate podocyte injury through directly activating the specific receptors. In the present animal experiment, PIO at dose of $10 \mathrm{mg} / \mathrm{kg}$ was unable to produce significant change in urinary sediment podocalyxin excretion compared with group DM, whereas the ability of preserving glomerular podocalyxin expression was dramatic. Multiple factors including local renal hemodynamic and inflammation may have influences on glomerular podocalyxin protein expression. Inevitably, different sensitivity based on different methods couldn't be ignored. These differences remain to be corroborated by extending the experiment period and amplify the samples in future.

A meta analysis published in 2010 on the use of TZDs in diabetes found that this therapy was associated with a substantial reduction in urinary protein excretion which was related with its roles of reducing reactive oxygen species (25), NF- $\mathrm{kB}$ activation and MCP-1 expression, interfering ERKL/2 pathway and blocking RAAS-inducing podocyte apoptosis in the early phase 
of diabetic nephropathy (26-29). TZDs are a class of powerful insulin sensitizer prescribed for the treatment of type 2 diabetics and produce a favorable lipid profile $(30,31)$. We also found that PIO-treatment groups exhibited effects in regulating lipid profiles, including a decrease in TG and LDL-c and an increase in HDLc. Interestingly, data from our studies illustrated that plasma HDL-c was dose-dependently increased with PIO therapy at the $8^{\text {th }}$ week. Much more samples and longer experiment period are needed to confirm this phenomenon.

A potential role for TZDs as therapeutic strategy in podocyte related diseases is warranted in multiple studies $(24,32)$. From our findings, PIO had definite podocyte protection by alleviating podocyte injury during the 8-week treatment periods. The mechanisms remain unclear. Several of them by which pioglitazone protect against DCKD have been proposed as the following ways. PPAR- $\gamma$ agonist rosiglitazone suppressed modulator of HG-induced signaling that acts through PKC- $\zeta$ but not AMPK and regulated VEGF and collagen IV expression by mesangial cells (33). Toblli and cols., reported that PIO at low dose given for 4-5 months reduced proteinuria and ameliorated renal damage and fibrosis mainly through antioxidant (34). Study by Makino and cols. revealed that gene expressions of podocyte structure-related genes as well as that of oxidative stress and lipid metabolism were restored concomitant with attenuation of albuminuria by PIO treatment (35). Previous study proved that pioglitazone could suppress high glucose-induced phosphorylation of $44 / 42$ mitogen-activated protein kinase and reduce $\mathrm{Bcl}-2$ and $\mathrm{p} 27$ (Kipl) protein levels in type 2 diabetes (36). Additionally, thiazolidinediones were found to modulate the glucocorticoid pathway and to exert direct protective effects on podocytes, similar to glucocorticoids (37). Apart from glucose-lowering action, pioglitazone ameliorates DCKD via cell cycle-dependent mechanisms. Miyata and Dan, disclosed that PIO reduced the renal accumulation of advanced glycation end products (AGEs) (38). Furthermore, our previous work both in animal and human studies have shown a direct renoprotective effect of TZDs by its anti-inflammatory mechanism, which maybe also contribute to its effects against kidney injury indirectly $(39,40)$.

In conclusion, our findings suggested that PIO could dose-dependently alleviate podocyte injury, which maybe related partially to effects in inhibiting the down-regulation of glomerular podocalyxin expression and decreasing urinary sediment podocalyxin excretion in streptozotocin-induced diabetic rats. However, more studies are necessary to elucidate the exact integrated mechanisms of the podocyte protection of PIO.

Acknowledgment: the research was financially supported by the Foundation of Anhui Education Bureau of China (No. 2006KJ318B) and by the Nature Science Foundation of Anhui Province of China (No. 01041181).

Disclosure: no potential conflict of interest relevant to this article was reported.

\section{REFERENCES}

1. Kumar PA, Brosius FC 3rd, Menon RK. The glomerular podocyte as a target of growth hormone action: implications for the pathogenesis of diabetic nephropathy. Curr Diabetes Rev. 2011;7:50-5.

2. Teiken JM, Audettey JL, Laturnus DI, Zheng S, Epstein PN, Carlson EC. Podocyte loss in aging OVE26 diabetic mice. Anat Rec (Hoboken). 2008;291:114-21.

3. Campbell KN, Raij L, Mundel P. Role of angiotensin II in the development of nephropathy and podocytopathy of diabetes. Curr Diabetes Rev. 2011;7:3-7.

4. Kritz W. Progressive renal failure-inability of podocytes to replicate and the consequences for development of gomerulosclerosis. Nephrol DialTransplant. 1996;11:1738-42.

5. Petermann AT, Pippin J, Krofft R, Blonski M, Griffin S, Durvasula $R$, et al. Viable podocytes detach in experimental diabetic nephropathy: potential mechanism underlying glomerulosclerosis. Nephron Exp Nephrol. 2004;98:e114-23.

6. Yu D, Petermann A, Kunter U, Rong S, Shankland SJ, Floege J. Urinary podocyte loss is a more specific marker of ongoing glomerular damage than Proteinuria. J Am Soc Nephrol. 2005;16:1733-41.

7. do Nascimento JF, Canani LH, Gerchman F, Rodrigues PG, Joelsons $G$, dos Santos $M$, et al. Messenger RNA levels of podocyte-associated proteins in subjects with different degrees of glucose tolerance with or without nephropathy. BMC Nephrol. 2013;14:214.

8. Xing Y, Ye S, HuY, Chen Y. Podocyte as a potential target of inflammation: role of pioglitazone hydrochloride in patients with type 2 diabetes. Endocr Pract. 2012;18(4):493-8.

9. Doyonnas R, Kershaw DB, Duhme C, McNagny. Anuria, omphalocele, and perinatal lethality in mice lacking the CD34-related protein podocalyxin. J Exp Med. 2001;194:13-27.

10. Skoberne A, Konieczny A, Schiffer M. Glomerular epithelial cells in the urine: what has to be done to make them worthwhile? Am J Physiol Renal Physiol. 2009;296(2):F230-41.

11. Miyazaki Y, Cersosimo E, Triplitt C, DeFronzo RA. Rosiglitazone decreases albuminuria in type 2 diabetic patients. Kidney Int. 2007;72:1367-73.

12. Setti G, Hayward A, Dessapt C, Barone F, Buckingham R, White $\mathrm{K}$, et al. Peroxisome proliferator-activated receptor- $\gamma$ agonist rosiglitazone prevents albuminuria but not glomerulosclerosis in experimental diabetes. Am J Nephrol. 2010;32:393-402.

13. Rees DA, Alcolado JC. Animal models of diabetes mellitus. Diabet Med. 2005;22:359-70.

14. Kanno K, Kawachi H, Uchida Y, Hara M, Shimizu F, Uchiyama M. Urinary sediment podocalyxin in children with glomerular diseases. Nephron Clin Pract. 2003;95:c91-9. 
15. Pavenstädt $\mathrm{H}$, Kriz W, Kretzler M. Cell biology of the glomerular podocyte. Physiol Rev. 2003;83:253-307.

16. Schmieder S, Nagai M, Orlando RA, Takeda T, Farquhar MG. Podocalyxin activates RhoA and induces actin reorganization through NHERF1 and Ezrin in MDCK cells. J Am Soc Nephrol. 2004;15:2289-98.

17. Nielsen JS, McNagny KM. The role of podocalyxin in health and disease. J Am Soc Nephrol. 2009;20:1669-76.

18. Hara M, Yamamoto T, Yanagihara T, Takada T, Itoh M, Adachi Y, et al. Urinary excretion of podocalyxin indicates glomerular epithelial cell injuries in glomerulonephritis. Nephron. 1995;69:397-403.

19. Lee YC, Li TM, Tzeng CY, Cheng YW, Chen YI, Ho WJ, et al. Electroacupuncture-induced cholinergic nerve activation enhances the hypoglycemic effect of exogenous insulin in a rat model of streptozotocin-induced diabetes. Exp Diabetes Res. 2011;2011:947138.

20. Uysal N, Yalaz G, Acikgoz O, Gonenc S, Kayatekin BM. Effect of $\mathrm{L}$-carnitine on diabetogenic action of streptozotocin in rats. Neuro Endocrinol Lett. 2005;26:419-22.

21. Ohga S, Shikata K, Yozai K, Okada S, Ogawa D, Usui H, et al. Thiazolidinedione ameliorates renal injury in experimental diabetic rats through anti-inflammatory effects mediated by inhibition of NF-kappaB activation. Am J Physiol Renal Physiol. 2007;292:F1141-50.

22. Toblli JE, Cao G, Giani JF, Angerosa M, Dominici FP, GonzalezCadavid NF. Antifibrotic effects of pioglitazone at low doses on the diabetic rat kidney are associated with the improvement of markers of cell turnover, tubular and endothelial integrity, and angiogenesis. Kidney Blood Press Res. 2011;34:20-33.

23. Yoshioka S, Nishino H, Shiraki T, Ikeda K, Koike H, Okuno A, et al. Antihypertensive effects of CS- 045 treatment in obese Zucker rats. Metabolism. 1993;42:75-80.

24. Kanjanabuch T, Ma LJ, Chen J, Pozzi A, Guan Y, Mundel P, et al. PPAR-gamma agonist protects podocytes from injury. Kidney Int. 2007;71:1232-9.

25. Sarafidis PA, Stafylas PC, Georgianos PI, Saratzis AN, Lasaridis AN. Effect of thiazolidinediones on albuminuria and proteinuria in diabetes: a meta-analysis. Am J Kidney Dis. 2010;55:835-47.

26. BaoY, Jia RH, Yuan J, Li J. Rosiglitazone ameliorates diabetic nephropathy by inhibiting reactive oxygen species and its downstream-signaling pathways. Pharmacology. 2007;80:57-64.

27. Hirasawa Y, Matsui Y, Yamane K, Yabuki SY, Kawasaki Y, Toyoshi T, et al. Pioglitazone improves obesity type diabetic nephropathy: relation to the mitigation of renal oxidative reaction. Exp Anim. 2008;57:423-32.
28. Jauregui A, Mintz DH, Mundel P, Fornoni A. Role of altered insulin signaling pathways in the pathogenesis of podocyte malfunction and microalbuminuria. Curr Opin Nephrol Hypertens. 2009;18:539-45.

29. Yuan X, Liu N. Pioglitazone suppresses advanced glycation end product-induced expression of plasminogen activator inhibitor- 1 in vascular smooth muscle cells. J Genet Genomics. 2011;38:193-200.

30. MiyazakiY, DeFronzo RA. Rosiglitazone and pioglitazone similarly improve insulin sensitivity and secretion, glucose tolerance and adipocytokines in type 2 diabetic patients. Diabetes Obes Metab. 2008;10:1204-11.

31. Vergès B. Effects of glitazones in the treatment of diabetes and/or hyperlipidaemia: glycaemic control and plasma lipid levels. Fundam Clin Pharmacol. 2007;21:15-8.

32. Yang HC, Ma LJ, Ma J, Fogo AB. Peroxisome proliferator-activated receptor-gamma agonist is protective in podocyte injury-associated sclerosis. Kidney Int. 2006;69:1756-64.

33. Whiteside C, Wang H, Xia L, Munk S, Goldberg HJ, Fantus IG. Rosiglitazone prevents high glucose-induced vascular endothelial growth factor and collagen IV expression in cultured mesangial cells. Exp Diabetes Res. 2009;2009:910783.

34. Toblli JE, Ferrini MG, Cao G, Vernet D, Angerosa M, Gonzalez-Cadavid NF. Antifibrotic effects of pioglitazone on the kidney in a rat model of type 2 diabetes mellitus. Nephrol DialTransplant. 2009;24:2384-91.

35. Makino H, Miyamoto Y, Sawai K, Mori K, Mukoyama M, Nakao K, et al. Altered gene expression related to glomerulogenesis and podocyte structure in early diabetic nephropathy of $\mathrm{db} / \mathrm{db}$ mice and its restoration by pioglitazone. Diabetes. 2006;55:2747-56.

36. Okada T, Wada J, Hida K, Eguchi J, Hashimoto I, Baba M, et al. Thiazolidinediones ameliorate diabetic nephropathy via cell cycle-dependent mechanisms. Diabetes. 2006;55:1666-77.

37. Agrawal S, Guess AJ, Benndorf R, Smoyer WE. Comparison of direct action of thiazolidinediones and glucocorticoids on renal podocytes: protection from injury and molecular effects. Mol Pharmacol. 2011;80:389-99.

38. Miyata T, Dan T. Inhibition of advanced glycation end products (AGEs): an implicit goal in clinical medicine for the treatment of diabetic nephropathy. Diabetes Res Clin Pract. 2008;82:S25-9.

39. Hu YY, Ye SD, Zhao LL, Zheng M, Chen Y. Hydrochloride pioglitazone decreases urinary TGF-beta1 excretion in type 2 diabetics. Eur J Clin Invest. 2010;40:571-57.

40. Zheng M, Ye S, Zhai Z, Chen Y, Li X, Yang G, et al. Rosiglitazone protects diabetic rats against kidney disease through the suppression of renal moncyte chemoattractant protein-1 expression. J Diabetes Complications. 2009;23:124-9. 